\title{
International consensus statement on the assessment of interprofessional learning outcomes.
}

Gary Rogers, Jill Thistlethwaite, Madeleine Abrandt Dahlgren, Ruby Grymompre, Monica Moran and Duepa Samarasekera

\section{Journal Article}

\section{Tweet}

N.B.: When citing this work, cite the original article.

This is an electronic version of an article published in:

Gary Rogers, Jill Thistlethwaite, Madeleine Abrandt Dahlgren, Ruby Grymompre, Monica Moran and Duepa Samarasekera, International consensus statement on the assessment of interprofessional learning outcomes., Medical teacher, 2016.pp.1-13.

Medical teacher is available online at informaworldTM:

http://dx.doi.org/10.1080/0142159X.2017.1270441

Copyright: Taylor \& Francis: STM, Behavioural Science and Public Health Titles http://www.tandf.co.uk/journals/default.asp

Postprint available at: Linköping University Electronic Press

http://urn.kb.se/resolve?urn=urn:nbn:se:liu:diva-135419

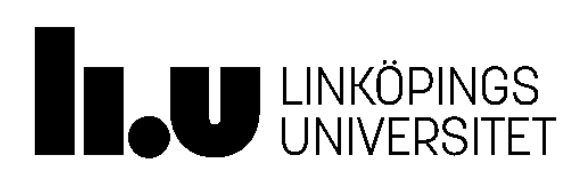




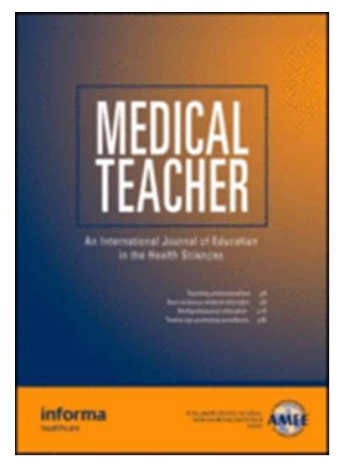

\section{International consensus statement on the assessment of interprofessional learning outcomes}

\begin{tabular}{|r|l|}
\hline Journal: & Medical Teacher \\
\hline Manuscript ID & Draft \\
\hline Manuscript Categories: & Articles \\
\hline Complete List of Authors: & $\begin{array}{l}\text { Rogers, Gary; Griffith University, School of Medicine } \\
\text { Thistlethwaite, Jill; University of Technology Sydney } \\
\text { Anderson, Elizabeth; University of Leicester Medical School } \\
\text { Abrandt Dahlgren, Madeleine; Linköping University, Medicine and Health; } \\
\text { Linköping University, Behavioural Sciences and Learning } \\
\text { Grymonpre, Ruby; University of Manitoba, College of Pharmacy } \\
\text { Moran, Monica; Central Queensland University, School of Human, Health } \\
\text { and Social Sciences } \\
\text { Samarasekara, Dujeepa; National University of Singapore, Medical } \\
\text { Education Unit }\end{array}$ \\
\hline Keywords: & \begin{tabular}{l} 
Assessment, Undergraduate < Phase of education, General < Profession \\
\hline
\end{tabular} \\
\hline
\end{tabular}

\section{SCHOLARONE ${ }^{\text {Tx }}$ \\ Manuscripts}


Title:

\section{International consensus statement on the assessment of interprofessional learning outcomes}

Short title:

IPL assessment consensus statement

Authors:

Gary D. Rogers ${ }^{1}$, Jill E. Thistlethwaite ${ }^{2}$, Elizabeth S. Anderson ${ }^{3}$, Madeleine Abrandt Dahlgren ${ }^{4}$, Ruby Grymonpre ${ }^{5}$, Monica Moran ${ }^{6} \&$ Dujeepa D. Samarasekera ${ }^{7}$.

Affiliations:

${ }^{1}$ School of Medicine and Health Institute for the Development of Education and Scholarship (Health IDEAS), Griffith University, Queensland, Australia

${ }^{2}$ School of Communication, University of Technology Sydney, Australia

${ }^{3}$ Department of Medical Education, The University of Leicester, United Kingdom

${ }^{4}$ Department of Medical and Health Sciences, Linköping University, Sweden

${ }^{5}$ College of Pharmacy, University of Manitoba, Canada

${ }^{6}$ School of Human Health and Social Sciences, Central Queensland University, Australia

${ }^{7}$ Centre for Medical Education (CenMED), National University of Singapore, Singapore

Correspondence details:

Professor Gary D. Rogers

School of Medicine

G40_8.75 Gold Coast Campus

GRIFFITH UNIVERSITY QLD 4222

Australia

Ph: +61756780326

Email: g.rogers@griffith.edu.au 


\begin{abstract}
Regulatory frameworks around the world mandate that health and social care professional education programmes graduate practitioners who have the competence and capability to practice effectively in interprofessional collaborative teams. Academic institutions are responding by offering interprofessional education (IPE); however, there is as yet no consensus regarding optimal strategies for the assessment of interprofessional learning (IPL).

The Program Committee for the $17^{\text {th }}$ Ottawa Conference in Perth, Australia in March, 2016, invited IPE champions to debate and discuss the current status of the assessment of IPL. A draft statement from this workshop was further discussed at the global All Together Better Health VIII conference in Oxford, UK in September, 2016. The outcomes of these deliberations and a final round of electronic consultation informed the work of a core group of international IPE leaders to develop this document.

The consensus statement we present here is the result of the synthesised views of experts and global colleagues. It outlines the challenges and difficulties but endorses a set of desired learning outcome categories and methods of assessment that can be adapted to individual contexts and resources. The points of consensus focus on pre-qualification (pre-licensure) health professional students but may be transferable into post-qualification arenas.
\end{abstract}




\section{Introduction}

Interprofessional education (IPE) occurs when 'two or more professions learn with, from and about each other to improve collaboration and the quality of care' (CAIPE 2002). This process aims to ensure that health professional students and practitioners have the capabilities required for effective collaborative interprofessional practice (IPP), which we have chosen to define as:

health and community service professionals working together, using complementary knowledge and skills, to provide care to patients, clients and communities, based on trust, respect and an understanding of each other's expertise (adapted from Canadian Medical Association 2007, p. 3).

In the context of health and social care service delivery globally, evidence continues to emerge in support of IPP achieved through IPE. The World Health Organization (2010) highlighted this evidence within a Framework for Action on Interprofessional Education \& Collaborative Practice (WHO, 2010). This document cites drivers for collaborative care models including: health care provider shortages; poor patient safety records; duplication of services; escalating costs; and limited access to the right services at the right time at the right location. It also identifies many possible benefits from IPP such as: reduction in lengths of hospital stay; improvements in quality of life for patients, clients and their families; improved access to care; and enhanced patient and client safety. Further, evidence suggests that highly collaborative teams experience reduced tensions and conflict, leading to improved job satisfaction, as well as enhanced recruitment and retention of health care providers (Zwarenstein et al 2009; Health Force Ontario 2010; Reeves et al 2013). Proponents of IPP assert that the needs of many patients 
and clients are beyond the expertise of any single health care provider and true patient- or clientcentred service requires IPP (Freeth 2001; Bridges et al 2011; van Dongen 2016).

Academic institutions worldwide have responded to the growing emphasis on IPP by embedding IPE in the curricula of health and human service professional programmes (see for example: Herbert 2005; Barr \& Ross 2006; Boyce et al 2009; WHO 2010; Rogers 2011; Gilbert 2014; Paterno \& Opina-Tan 2014; Wilhelmsson et al 2009; Anderson et al 2015; Grymonpre 2016). Integration of IPE in pre-licensure programmes has been further driven by reports and initiatives across a range of health and human service programmes. From the US, the Lancet Report identified IPE as a key factor in transforming medical, nursing and public health education in the $21^{\text {st }}$ century (Frenk et al 2010). One of ten recommendations in The Future of Medical Education in Canada report relates to advancing inter- and intra-professional practice (Association of Faculties of Medicine of Canada 2015).

In recent years, drivers have also included professional regulatory authorities, who seek integration of IPE standards into the accreditation of health and social care programmes. Accreditation is a complex process that assesses a programme's compliance with national professional standards and serves as an incentive for change (Curran et al 2005). As such, accreditation strongly influences the quality and content of education programmes for health professionals (Gelmon et al 1999; Kassebaum 1992; Kassebaum \& Cohen 2000; Schwarz 1992; Frenk et al 2010). In Canada (CIHC 2016) and, in relation only to the post-licensure arena, in the United States (Joint Accreditation 2013) accreditation organisations for different professions have recently begun to collaborate to create unified processes that promote IPE. These 
developments offer models for closer collaboration between professional accreditation bodies to this end.

In addition to publication of the WHO Framework for Action, 2010 saw the promulgation of the Sydney Interprofessional Declaration, a consensus communiqué from the fifth global All Together Better Health Conference in Australia. The declaration asserted, in Article 1, that '....all users of health and human services shall be entitled to fully integrated, interprofessional collaborative health and human services' and went on in Article 3 to place an onus on providers of pre-licensure health professional education, as follows:

\section{Health worker education and training prior to practice shall contain} significant core elements ... of interprofessional education. These ... shall contain practical experiences ... [and] ... be formally assessed. (All Together Better Health 5 International Conference participants 2010, p. 1)

In the six years since the Sydney Declaration, there has been much activity around the definition of interprofessional learning (IPL) outcomes (Thistlethwaite et al 2014), but so far no global consensus has emerged about the range of outcomes to be assessed and how that assessment should be undertaken.

A recent review of pre-qualification IPE evaluations highlighted that, of the ninety studies included, only five reported on assessment of student knowledge via a written test and only four reported on an assessment of student performance through observation or interviews (Thistlethwaite et al 2015). An audit of IPE at Australian higher education institutions (The Interprofessional Curriculum Renewal Consortium 2013) found that, of 70 activities, $59 \%$ were 
assessed, with the most common assessment methods being required attendance, essays and presentations.

Consensus about assessment processes and procedures is needed to satisfy academic, professional and regulatory bodies. However, the formation of consensus needs to recognise the tensions between the pressures on faculty members to appease regulators and produce the types of practitioners required by service organisations, on the one hand, while considering the needs of patients and clients for person-centred, effective and efficient high quality care, on the other (see Figure 1).

\title{
INSERT FIGURE 1 ABOUT HERE
}

\begin{abstract}
At the same time, while most authors agree that IPE is important, there is little agreement on how to compile a curriculum theme throughout pre-registration education, aligned with learning outcomes, that includes assessment of IPL. Reeves $(2012$, p.254) further points out that 'we are not clear about how to robustly measure (assess) the many different statements which make up the interprofessional competency'. This is partly because, in health professional education broadly, we are focussed on personal accountability for registration purposes, rather than team accountability and responsibility. In addition, there remains considerable uncertainty as to how to describe fully what the World Health Organization terms, 'collaborative practice-ready' (WHO 2010, p.7) learners at the pre-registration and various post-qualified levels of a professional career trajectory.
\end{abstract}


This consensus statement aims to crystallise current global understandings of the assessment of IPL, supported by evidence and expert opinion, as well as to offer clarity concerning minimum standards, while highlighting the remaining research questions that require action.

\section{Methods}

In response to an invitation by the Program Committee for the $17^{\text {th }}$ international Ottawa Conference on the Assessment of Competence in Medicine and the Healthcare Professions, held in Perth, Australia in March 2016, we began a collaborative process with the aim of reaching a global consensus on the key questions related to the assessment of interprofessional learning outcomes.

Prior to the conference, we formed a core writing group through invitations to IPE scholars from Europe, North America, Asia and Australia; as well as a range of professions including nursing, medicine, pharmacy, occupational therapy, and health professional education. All had experience of aligning IPE within health and social care curricula. The group scoped the key issues to enable a full and open debate, using an interactive workshop design, at the Ottawa Conference (first round of consultation). We then developed a draft consensus statement, which guided further discussion in a pre-conference workshop at the eight international All Together Better Health conference, held in Oxford, UK in September 2016 (second round of consultation). Workshop participants from around the world, including developed and resource constrained settings, offered their perspectives. They discussed key questions related to the assessment of interprofessional learning outcomes. Both sessions were audio recorded and a note taker recorded key points of feedback. The writing group then synthesised all comments and feedback to develop revised points of consensus, that were circulated to all participants from both 
workshops, including key scholars from less well-resourced settings, for comment (third and final round of consultation). We undertook a further revision, informed by input received, to produce the final consensus statement presented here.

Prior to the conference workshops, the writing team decided to limit the scope of this consensus statement to the education of health and social care students prior to first registration or licensure. We made this decision in order to render the task of developing the statement manageable within the time and resources available, as well as to respond directly to the entreaty of Article 3 of the Sydney Interprofessional Declaration. We believe that the statement also has important implications for the post-registration and continuing professional development domains and plan to address these more directly in an extension of the statement to be developed in the future. We also made the decision to adopt a view of the concept of 'interprofessional' that encompasses all persons who contribute to the health and wellbeing of a patient, client or community, including those who in some jurisdictions may not be considered 'professionals', as well as workers in related occupations such as teachers and police officers.

The writing team was acutely aware that health and education systems differ across the world. Through the consultations we deliberately sought comment on the interpretation and implementation of the statement in diverse cultural settings but we recognise that further refinement is likely to be necessary as educators attempt to make use of it around the globe. This may be particularly so in societies where hierarchical structures are culturally valued. With these concerns in mind we invite feedback from readers of this paper that may contribute to future revisions. 


\section{Consensus Themes}

Seventy-five contributors from 15 countries shared their views, which were synthesised by the global writing team.

The consensus themes fell under three overarching categories, some with subcategories, as follows:

- Context:

i) The purposes of the assessment of interprofessional learning outcomes

ii) How assessment should be applied over the course of a learning programme

- The assessment journey of teacher and student:

i) What should be assessed

ii) How to assess

iii) How feedback to enhance further learning should best be provided

- Gaps in the evidence base requiring further scholarly enquiry.

\section{Context}

\section{i) The purposes of interprofessional assessment}

As Gilbert (2005) has argued, one of the most significant barriers to the effectiveness of IPE is the perception on the part of some students and educators that it is a peripheral 'add-on', rather than 'an integral and necessary component in the education of health and human service professionals, regardless of discipline' (p.101). Oandasan and Reeves (2005) suggest that 'students sometimes feel that interprofessional learning is not as important as their profession 
specific experiences' (p.26). For this reason, many see assessment as having a critical role in conveying messages to stakeholders (including licensing bodies, administrators, educators, patients, clients and the general community, as well as learners themselves) concerning the significance of interprofessional learning. Boud (2000) defined assessment as:

an act of communication about what we value. It transmits not only our views about what is important for our subject, but is an act of cultural communication transmitting what the collective 'we' intends (p160).

\begin{abstract}
As Muijtjens and colleagues observed in 1998, 'tests and examinations drive student learning' (p. 81) and while, like most truisms, this is an over-simplification of reality (McLachlan 2006), there is no doubt that the inclusion of assessment in an interprofessional programme promotes engagement on the part of students who may otherwise tend to pay more attention to the acquisition of uniprofessional learning.
\end{abstract}

There has never been a more urgent period in the history of healthcare for promotion of patient and client safety (Dixon-Woods 2010), underlining the importance of effective assessment of IPL to ensure that graduating practitioners are able to practise collaboratively and work effectively and safely - in teams (Ladden et al 2006).

There is also evidence that patients and clients want professionals to communicate effectively and many become involved in the development and delivery of interprofessional learning because of these aspirations (Manidis et al 2009; Anderson et al 2011). This effect is also recognised by interprofessional educators (Carlisle et al 2004). Moreover, there is anecdotal evidence that people from indigenous communities in different parts of the world, in particular, frequently 
complain that health care workers don't, as Carlisle's group (2004) put it, 'talk to each other' (p. 545). These expectations begin to articulate IPL as part of a 'social contract' between the health care professions and the citizens they serve (Cruess \& Cruess, 2008).

There are two key components to the purpose of assessment: it both assesses learning and also in itself drives learning (Thistlethwaite 2015). As Imanipouri \& Jalili (2016) have recently observed:

\author{
Viewing assessment as a method for improvement and learning instead of \\ viewing it as only a tool for accountability is the most important change \\ that [has] occurred in thinking about assessment (p. 47).
}

Frequently, reference is made to assessment as either 'summative' or 'formative', with calls for IPE to address both of these areas (Barr et al 2016). Summative assessment is the endpoint of a particular course, programme or university degree and compares a learner's achievement through marks or grades with a previously-set standard or benchmark. Summative assessment aims to answer the questions: 'has the learner shown evidence of adequate learning?' and 'has the learner met the required standard?' Formative assessment, in contrast, is a process that provides information both to learners and to educators about the progress of each learner, in order to identify areas of strength or weakness. Thus, formative assessment is about 'feedback' and 'dialogue' between learner and teacher. Ideally all summative assessment should have a formative component, but this is often missing from high stakes examinations that result solely in a mark or a pass/fail decision. Summative assessment assesses learning (assessment of learning) while formative assessment supports and enhances learning (assessment for learning). Formative assessment of skills-based activities and complex tasks such as teamwork should involve frequent 
observation with constructive and timely feedback. When done well, therefore, it is time and resource intensive.

Considerations of the purpose of assessment should include the identification of standards against which the performance of learners can be judged. Over the last two decades, behaviourist, outcomes-focused curricula in health care have turned to the use of competence-based assessments (Frank et al 2010) and there has been a plethora of papers that both support and refute this approach (see, for example, van der Vleuten \& Schuwirth 2005; Lurie 2012). The use of 'a competence' offers a clear structure for assessment. Competence is aligned to what Miller (1990) outlined as a combination of knowledge with subsequent ability to practise. In particular, it is an amalgamation of knowledge and understanding in the cognitive domain ('Knows' and 'Knows How'), with performance in the psychomotor domain (in 'Shows How') and action ('Does', which combines all three of Bloom's domains [Bloom 1956]). Barr (1996) has proposed that the competence-based approach is compelling, arguing that:

$$
\begin{aligned}
& \text { [c]ompetency-based learning will have to be embraced if interprofessional } \\
& \text { education is to secure its place in emerging models of professional and } \\
& \text { vocational education. Only then will interprofessional education be ready to } \\
& \text { subject its outcomes to critical reviews in terms not only of collaborative } \\
& \text { attitudes but also collaborative behaviour (p. 350). }
\end{aligned}
$$

However, as Fraser and Greenhalgh (2001) argued a decade and a half ago, the concept of competence ('what individuals know or are able to do in terms of knowledge, skills, attitude' [p.799]) is insufficient to describe the qualities necessary for effective practice in a complex health environment. They suggested 'capability' as a higher level outcome that encompassed the 
elements of competence as well as 'the ability to adapt to change, generate new knowledge, and continuously improve performance' (p. 799). Wilson and Holt (2001) reached similar conclusions at about the same time.

Other conceptual descriptors for the outcomes of health professional (including interprofessional) education include entrustable professional activities (ten Cate et al 2010) and threshold learning outcomes (O’Keefe 2014; Rogers 2011), while Lurie (2012) has suggested that, because interprofessionalism is, like many others, mainly a social competence, it may be more appropriate to abandon reductionist approaches to measurement altogether and rather embrace complexity in relation to 'patterns of human performance in the clinical setting' (p. 56).

\section{Points of consensus on the purposes of the assessment of interprofessional outcomes}

- To raise the value of the learning for all stakeholders and promote learner engagement

- To verify the capabilities for safe effective practice

- To meet the needs and expectations of patients, clients and communities, as well as carers and families, for effective cooperation and interprofessional communication between health and social care workers

- To measure what learning has taken place and support further learning

- To offer insights into the achievement of a minimal standard using frameworks relating to competence or capability

\section{ii) How assessment should be applied over the course of a programme}

Best practice in assessment requires curriculum alignment, that is, it must assess the defined learning outcomes of the educational programme (Biggs \& Tang 2007). In addition, educators need to decide what should be assessed and when, in relation to the learning opportunities and learning activities in place to help students to meet the required outcomes. At the current time in 
some institutions, not all health professional and social care students have sufficient experiences and relevant exposure to IPL. Assessment, therefore, cannot be acceptable or feasible until there is equity of opportunity in learning - though all students do not need to have exactly the same experiences. This requires a learning trajectory with early theoretical learning, as well as learning activities - simulated or clinical - where team working and collaborative practice can be observed, practised and potentially assessed (Anderson et al 2015). Feedback, formative and summative assessments need to be made clear to students from the outset of their programmes.

The introduction of a new method of assessment requires additional faculty development and appropriate resources to ensure equity across all health professions. As Steinert (2005) put it:

Faculty development can play a unique role in promoting IPE by addressing some of the barriers ... that exist at both the individual and the organizational level, and by providing individuals with the knowledge and skills needed to design and facilitate IPE (p. 60).

\begin{abstract}
Action will be needed in many settings to ensure that faculty, clinical supervisors and preceptors gain the capacity to assess students effectively in relation to interprofessional learning outcomes. Reeves and colleagues (2016) have argued that IPE facilitation is influenced by contextual characteristics such as resources and technology, facilitator experience such as preparation and support, as well as facilitator strategies such as reflection and feedback.
\end{abstract}

Faculty development for assessors remains under researched, both within uniprofessional and interprofessional education as outlined in the final section of this statement. 
Points of consensus on how assessment should be applied over the course of a programme

- Formative and summative assessment should be critical elements within a programmatic approach to interprofessional education, where appropriate assessments are utilised to promote learning and to measure learning outcomes of increasing complexity across programmes

- The availability of appropriate interprofessional learning opportunities is a critical prerequisite to the fair assessment of interprofessional capabilities

- Appropriate developmental opportunities for educators and assessors are an inherent requirement to the effective implementation of interprofessional assessment processes.

\section{The assessment journey for the learner and teacher}

i) What to assess

Questions around the desired outcomes of IPE and the language through which these should be expressed were discussed extensively during the consensus process. A large number of frameworks - utilising a range of descriptors, such as competencies, capabilities (as discussed above) and various species of learning outcomes - already exists (see a review by Thistlethwaite et al 2014, and also Rogers 2011, UCSF 2014, Finnemann et al 2016, Haruta et al 2016, Interprofessional Education Collaborative 2016).

[INSERT TABLE 1 ABOUT HERE] 
After due consideration, the writing team has decided that there would be little value in attempting to reach consensus on either the outcome concept to be used to describe these desired characteristics or their detail. Rather, we have elected to present a thematic summary of the broad areas that the frameworks encompass and would encourage educators to ensure that they consider each of these areas when drawing from the wide array of available 'menus' (including individual profession- and jurisdiction-specific accreditation standards), to formulate the intended outcomes of their own planned interprofessional learning programmes.

As yet there is no empirical evidence to determine which areas of outcome need to be assessed and achieved in order to ensure that graduates can provide effective collaborative care that benefits patients, clients and communities, at each stage of training. There is, however, considerable consistency between the core domains of all the available interprofessional frameworks. The four most prominent of these were reviewed and compared by Thistlethwaite and colleagues (2014) and are summarised in Table 1. On the basis of this work and by consensus, the following are recommended as key thematic areas to be assessed:

1. Role understanding: This area includes outcomes that confirm an understanding of the roles, responsibilities, values and contributions of the health professions that the learner is most likely to encounter and work with in their future practice, including the profession that they are seeking to enter themselves. This is a concept that the first author has dubbed 'health professions literacy', though some members of the consensus process thought that the full original description of this capability (see Teodorczuk 2016) implied a depth of understanding that was unlikely to be fully achieved, particularly in preregistration health professional programmes. 
2. Interprofessional communication: This theme includes outcomes that confirm an ability to communicate effectively and respectfully with colleagues in other professions. It encompasses the importance of listening, negotiation, conflict management and resolution, as well as exploring and respecting values (though not necessarily agreeing with them all).

3. Interprofessional values: This theme includes outcomes related to the incorporation into the learner's world-view of values consistent with effective IPP. These include collegiality, respect for persons, a critical view of established hierarchy, client- and patient-centredness, appreciation of diversity, honesty, integrity and reliability, as well as a commitment to interprofessional continuing education across their professional life after graduation. We recognise that such outcomes may be difficult to measure directly though some methods do exist (see 'How to assess' below) - and will often be assessed indirectly through their impact on observable behaviours.

4. Coordination and collaborative decision-making: This theme includes outcomes related to the ability to coordinate one's professional activities collaboratively with colleagues, as well as with patients, clients, carers, families and communities, in order to synthesise diverse opinion and optimise care and services provided. It incorporates advocacy, leadership and followership capabilities.

5. Reflexivity: Outcomes in this area concern acquisition of the ability to monitor and reflect upon the effectiveness of interprofessional collaborations involving one's self and others, throughout one's career, with the aim of continuous improvement. 
6. Teamwork: IPP is not solely about teamwork, in the traditional sense of a bounded colocated group of professionals who identify as a team, meet regularly and reflect on performance. According to Hammick and colleagues (2009), a team is:

a small number of people with complementary skills, who are committed to a common purpose, performance, goals and approach, for which they are mutually accountable (p. 39).

However, this theme does focus on what teams are and how they function within healthcare; what makes for an effective collaborative team; barriers to teamwork; accountability; team dynamics and power relationships.

\section{Points of consensus on what to assess}

- Assessment of interprofessional learning should include outcomes in the following six domains: role understanding; interprofessional communication; interprofessional values; coordination and collaborative decision-making; reflexivity; and teamwork

ii) How to assess

The ways we assess are always situated and contextualised. Traditional assessment methodologies need to be adapted and modified creatively by educators in order to be fit-forpurpose in the interprofessional setting, but, as with assessment in the health professions in general, interprofessional assessment must: measure what was intended; offer a high pay-off so 
that students value formative feedback in preparation for summative outcomes; and be valid, reliable and equitable. Above all it must be feasible, affordable and acceptable for all stakeholders, as well as acknowledging the sensitivity of all things interprofessional while encouraging learning and not detracting from the enjoyment of learning with others.

There was strong agreement that a combination of assessments is required that looks to both the individual learners and their performance within a group or team setting.

The assessment of teamwork remains an important challenge. Assessment of health professionals and students for certification purposes is predominantly the assessment of individuals, which is appropriate in most situations. However, while IPE does not focus solely on teamwork, teamwork competencies related to interprofessional practice are important items for assessment. Assessment of teamwork and collaborative practice logically should involve an assessment of the whole team as well as individual performance contributing to teamwork and collaboration. While the ability to work in a team is enhanced by a theoretical knowledge of teamwork and team processes in general, and the roles and responsibilities of the relevant health professions specifically, assessment of teamwork in health and social care should ideally be undertaken through observation of students working in teams and carrying out teamwork tasks. In the early stages of an educational programme, these tasks may be non-clinical projects, but in the later stages they should be clinically relevant, involving authentic simulation and, ideally, tasks in real clinical settings (work-based assessment).

We acknowledge that it is impossible to provide all learners with exactly the same experiences during their programmes. Health and social care students work in different types of interprofessional teams for varying time periods, making observation of their teamwork 
challenging. A team may be formed specifically for the purpose of assessment, for example for a simulation or an observed structured clinical examination (OSCE). While this type of 'teamwork' mimics such team tasks as the response to a cardiac arrest, when teams form in response to an incident, it is not as authentic for other clinical situations when teams take time to form, 'gel' and thus to perform optimally. For these reasons, a 'team' of students formed specifically to be assessed for their collaborative skills is unlikely to function well (Oakley et al 2004).

The outcomes that we are trying to assess in this area remain somewhat nebulous, utilising phrases that are difficult to define such as 'being a team player' and 'collaborative working'. Further research is required to articulate and agree constituent elements across the range of professional practice, scoping what novice pre-licensure students can reasonably achieve, as opposed to the expert or master with many years of professional experience. A major issue is knowing what 'competent to enter practice' is, as we don't have data from practice to help to set this level.

Academic, professional and interprofessional considerations and requirements often conflict. There may be a specification on the part of some accrediting bodies that students may only be assessed by members of the same profession. Differences in educational cultures across the professions (and between nations) may also hamper the development of universally acceptable and feasible assessments for interprofessional learning outcomes and competencies (Dunworth 2007).

A wide range of possible activities for the assessment of interprofessional learning outcomes is available, as follows: 
Conventional assessment of health professions literacy. Basic role understandings, as a prerequisite to higher-level interprofessional learning, can be assessed through conventional techniques such as candidate-completed short answer questions or well-crafted, scenario-based, multiple choice questions (Morrissey et al 2014).

Team-based project. Students in interprofessional teams can undertake small projects such as community visits, writing patient leaflets, hospital audits then produce a report, an artefact (such as an art work, poster or video), or give a presentation (Anderson \& Lennox 2009).

Observation in simulation. Simulation - particularly the utilisation of extended, multi-method, interprofessional simulation activities (Rogers et al 2014a) - provides the opportunity for learners' teamwork and interprofessional communication skills to be observed in a relatively controlled and predictable environment. In these settings it is quite feasible for assessors to rate students' demonstration of particular capabilities on simple Likert-type scales, provided that careful calibration and benchmarking is undertaken to ensure reliability of assessments. In simulation-based education, students are also engaged as observers of peers enacting simulation. Their observations can be used for formative assessment and contribute to the learning outcomes of interprofessional simulation training.

Observation in practice. Assessment through supervisor observation in real patient- or clientcare practice is a feasible and time-honoured methodology, but has tended to focus at a more 'global' level than on individual capabilities. Recently, these workplace-based assessment (WBA) approaches have been extended to include assessment of interprofessional collaborative capacity though initiatives like the Australian Medical Council's 'Intern Assessment Form' (which is also being used in the assessment of senior medical students). This document asks 
clinical supervisors to rate learners' performance in relation, among other domains, to the extent to which they appear to 'respect the roles and expertise of other healthcare professionals, learn and work effectively as a member or leader of an interprofessional team, and make appropriate referrals', rating them on a five-point Likert-type scale ranging from 'Works in a way that disrupts effective functioning of the inter-professional (sic) team' to 'Works effectively as a member or leader of the inter-professional (sic) team and positively influences team dynamics' (Australian Medical Council 2014).

A frequently encountered problem with observation in clinical, rather than simulated, settings is the difficulty of having learners and observers in the same place at the same time and with the same protected time. For observation of interprofessional clinical activities there is the added difficulty concerning whether one professional will dedicate time to observe learners from a range of professions.

Reflective journaling. Reflective journaling is a well-established educational technique in health professional education (Mann et al 2009) and has the potential to allow assessment of learning in the affective domain (according to Bloom's original taxonomy [Krathwohl 1956]) in association with emotionally impactful experiences in clinical or simulated settings. Recently this approach has been utilised to identify and assess examples of affective learning related to interprofessional values during extended simulation experiences (Rogers et al 2012; Rogers et al 2014b).

Team-based critique. Scholarship in relation to clinical placement emphasises the importance of participation over passive observation for optimal learning to occur (Dornan et al 2007). However, active or purposeful observation can still have real learning benefit (Graffam 2007). There has been recent interest in devising 'capstone' (pre-graduation) assessment activities that 
allow students to apply the understandings of collaborative practice they have gained through an interprofessional learning programme by undertaking deliberate critical observation of a practitioner team into which they have been placed. Students are required to identify and describe examples of effective and less effective collaborative practice they have observed between the practitioner team members, as well as the reasons for these evaluations, and make suggestions for how the team may improve its collaborative function. These observations form the basis of a written assessment piece undertaken toward the end of their study programme. This strategy has the advantage of being simple to organise and inexpensive to implement but might nonetheless provide educational benefit in terms of consolidation of learning, as well as summative assessment of higher level learning outcomes. A main drawback may be the numbers of such written assignments that need to be assessed - in some institutions across all professional learners the number may be in excess of 1000.

An interprofessional portfolio. This is a collection of diverse evidence intended to confirm that an individual has met the defined learning outcomes or achieved the required competencies for progression within a programme or for certification. A portfolio may also be termed 'an interprofessional passport' (see for example College of Health Disciplines, University of British Columbia 2014). Portfolios usually include two sections: (i) elements provided by educators and assessors including the list outcomes or competencies, suitable interprofessional learning activities and a template for completion; and (ii) elements provided by the learners including discussion of why the outcomes are important for their practice, activities undertaken and evidence for their achievement of the learning outcomes. Portfolios may contain evidence from all of the other assessment activities discussed in this section. 
The method again acknowledges that, while all learners must meet the same outcomes, they may not have the same learning activities or experiences. The assessment becomes learner-centred as students need to choose activities and reflect on the evidence required to show that they have achieved the required outcomes.

Portfolios have become more popular because of the need for students to learn to select critical learning moments for revalidation and appraisal after they have qualified (see General Medical Council 2012 for examples). In the UK, undergraduate students have had access to the National Health Service ePortfolio to prepare them for managing personal development after graduation and the drop down functions, such as 'reflection', offer places to document relevant IPL (NHS Education for Scotland 2016). Students completing IPE across an undergraduate curriculum have found this valuable and the tool appears to be easily adapted and accepted across different professions (Domac et al 2015). In a recent study, analysis of reflective writing following IPE within a portfolio has confirmed that students can clearly articulate learning of knowledge and consider how they will frame their practice as a result (Domac et al 2016).

Other examples of interprofessional portfolios can be found at the websites listed in the box.

\section{[INSERT BOX 1 ABOUT HERE]}

Peer assessment. Self and peer assessment are increasingly being used to assess group and teamwork in university settings. This might be based on practical considerations such as difficulties in finding clinicians and educators to observe students, but it is also supported by learning theory that emphasises the importance of engaging students in their own learning. One innovative tool for this purpose is SPARK, which is web-based (Freeman \& McKenzie 2002). 
Students working in teams assess their own and each other's performance against outcomes defined for the activity. Self-assessment can be compared to the peer assessment and all judgments are de-identified.

Tools. There is no shortage of surveys, scales, tools and instruments in relation to teamwork and attitudinal aspects of interprofessionality. These have been developed and used for various purposes including: evaluation of interventions to improve team performance; evaluation of imputed interprofessional educational outcomes; attitudes to interprofessional learning and practice; assessment of team performance and assessment of team behaviours. Such tools may be completed by:

- individuals in relation to their perceptions about other professions, interprofessional learning itself or some aspect of their team's functioning such as collaboration, job stress, job satisfaction and communication (i.e. self-report of belief, behaviour or performance); or

- one or more assessors, utilising behavioural markers during observation of a team in action at a specific location (for example in the emergency department or operating theatre) or during a specific task in a simulated or real care situation. This second group of tools seeks to facilitate and codify the gathering of information through the observational approaches described above.

Several self-completed questionnaires and scales have been developed over the last two decades and utilised particularly as pre- and post-tests for the evaluation of interprofessional learning programmes. The Readiness for Interprofessional Learning Scale (RIPLS) (Parsell \& Bligh 1999 ) is perhaps the best known, but the many other examples have been catalogued and 
compared by the Canadian Interprofessional Health Collaboration (CIHC 2012) and by Oates and Davidson (2014). Contributors to the consensus process generally believed that self-completed questionnaires had little to contribute to the summative assessment of the achievement of interprofessional learning outcomes by individual learners due to concerns about: the validity of scales (Mahler et al 2015; Schmitz \& Brandt 2015; Oates \& Davidson 2014); the veracity of selfreporting; and a philosophical recognition that such scales are, of their nature, reductionist, aiming to compress the complex phenomena of interprofessionality into a small number of numerical values.

The following tools have been developed to facilitate the organisation and recording of observations of performance either in real-time (in clinical settings or simulation), or video recordings. It is important to note that tools developed to assess the performance of established teams are unlikely to be suitable for the assessment of teams comprised of pre-registration health professional students.

- $\quad$ ICAR (interprofessional collaborator assessment rubric) (Curran et al 2011).

This is a detailed tool for the assessment of observable teamwork behaviours and may be used for individuals within a team or for the team as a whole. It has six domains with several dimensions in each: communication; collaboration; roles and responsibility; collaborative patient- or client-centred approach; team functioning; and conflict management and resolution. Learners are graded as: not observable; minimal; developing; competent; and mastery. The ICAR is quite complex and ideally should be used on multiple occasions with repeated observations. 
- $\quad$ Interprofessional OSCE (iOSCE) (Simmons et al 2011).

While stations may be developed locally, this tool includes behavioural indicators for teamwork that are generic. There are four items and a 0-3 grading: demonstrates knowledge and understanding of, and respect for, the roles of different members of the team; demonstrates ability to work well with different team members; has ensured all significant aspects of management have been addressed by a member of the team; does not duplicate information provided by a colleague. Simmons' group's paper (2011) describes the development of the iOSCE but there are, as yet, no data on its usage.

- $\quad$ Team OSCE (T-OSCE) (Hall et al 2011; Solomon et al 2011; Symonds et al 2013).

Also known as the McMaster-Ottawa T-OSCE, this is a scenario-based assessment with scenario-specific content and collaborative practice competencies. It involves observation of students in teams. There are six core objectives each containing several items: communication; collaboration; roles \& responsibilities; collaborative patient and familycentred approach; conflict management and resolution; and team functioning, each on a 9 point scale.

- $\quad$ TTOFT (interprofessional teamwork observation and feedback tool) (iTOFT Consortium 2015; Thistlethwaite et al 2016). There are two versions of this tool. The basic version is intended for the observation of junior students and has 11 items in the two domains of: shared decision making; and working in a team. The advanced form is for more senior students or novice health professionals and has 10 items in the four domains of: shared decision making; working in a team; leadership; and patient safety. Both versions have the same grading: not applicable to this activity; inappropriate; appropriate; responsive. 


\section{Points of consensus on how to assess}

- Assessment of interprofessional learning outcomes should, as a minimum, include: candidate-completed conventional assessment of role understanding; and observational assessment of individuals interacting interprofessionally, either in simulated or real patient and client care settings. The observational assessment may involve direct rating of learning outcome areas or utilise specifically-designed tools

- The assessment of the performance of teams (as opposed to individuals interacting in teams) remains problematic in the pre-registration domain and requires further research and development before it can be supported

- Techniques to assess affective learning related to interprofessionalism in the reflective journals of learners have promise and warrant further investigation

- The use of critical writing on the collaborative practice effectiveness of practitioner teams into which learners have been placed has the potential to provide consolidation of interprofessional learning, as well as summative assessment of understanding, toward the end of pre-registration programmes, also warrants further evaluation

- The use of learner-completed tools and scales to measure attitude or perceived confidence is not generally recommended as an element of the summative assessment of interprofessional learning outcomes, though some such tools may have a place as part of a portfolio assessment process. 
iii) Feedback to enhance student learning

Feedback is an integral part of the assessment process that aligns closely with the concept of formative assessment described above. Feedback is currently undergoing a reconceptualization and is seen as vital for motivation and impact when used appropriately (van de Ridder et al 2015). Optimal feedback should no longer be seen as a passive activity on the part of the learner, since 'information provided to students is used to influence their subsequent task performance' (Molloy \& Boud 2013, p. 19). Thus, learners need to adopt an agentic role, reflecting on and actively assimilating feedback in order to make appropriate changes in their subsequent performance. This is seen as integral to interprofessional learning, where personal insight and the ability to reflect are seen as critical learning outcomes in their own right. In this conception, feedback is a two-way process and learners are encouraged to seek out feedback rather than wait for it to be given to them. In many instances feedback is received following formative assessments; however, feedback takes place throughout teaching, both informally in a classroom when checking for understanding and opportunistically in clinical practice, where experienced practitioners may indicate how a student can progress their competence or capability.

In clinical settings students are frequently reluctant to solicit feedback and may not be sure whom to approach in a busy workplace. If a request for feedback is denied, learners may be demotivated and less likely to solicit comments in the future. Informal feedback processes may be rare due to workforce pressures. More formal systems of WBA are therefore being put into place to give students and clinicians a more structured feedback process (for example the miniCEX in medicine - Norcini et al 2003) but this is still largely contingent on goodwill and there is a need for protected time. A newly developed approach is to use multi-source feedback, 
collecting the views of patients, clients and other professionals in clinical settings (Thompson et al 2016).

Feedback is a continuous process, focuses on the individual's strengths and weaknesses, should always occur before any formal summative assessment and should cover the domains of knowledge, skills, attitudes and behaviour. Some of the observational assessment tools outlined earlier, such as the iTOFT, collect useful feedback that can be placed within a curriculum.

\section{Points of consensus on feedback}

- The provision of accurate, timely, feedback to learners on their progress toward achievement of interprofessional learning outcomes is a critical component of health professional education programmes

- Feedback during interprofessional learning should be seen as an active process that emphasises the agency of the learner as an active seeker of feedback on the basis of which they can improve their performance.

\section{Gaps requiring further research and scholarship}

\section{Understanding the broader impact of assessment in IPE}

There remains an urgent need to understand the impact of IPE from a societal perspective, including its influence on health outcomes (IOM 2015). This larger gap includes measurement of the specific effect of the assessment of IPL outcomes as a critical component of IPE.

Specifically, there is a need to define clearly what interprofessional competence or capability actually mean at the point of first entry to practice and then how measurement of their attainment, or not, impacts on the health outcomes of patients, clients and communities. 
Given the complexities that inhere in the assessment of team performance (as opposed to the performance of individual learners within team-based activities) in the preregistration domain, further scholarship will be required to confirm that such assessment is actually necessary to the improvement in health outcomes prior to its being routinely recommended.

\section{Identification of the minimum required suite of IPL assessments}

Further scholarly work is needed to define the nature, frequency and timing of a minimum suite of assessment activities required, across a constructively-aligned health professional curriculum, to ensure valid and reliable verification of interprofessional capability at graduation. This inquiry needs to cover a number of issues including: the focus of assessment on the individual or the team; the number of assessors required per student or team; whether assessors should be from same professional background as the examinee or a different profession; how assessments should be moderated; and what remediation processes should be utilised.

Further work is specifically recommended in the promising areas of: the assessment of reflective journaling to identify affective learning; and the utilisation of written assessment activities towards the end of programmes where the learner is placed in a critical posture in relation to the collaborative practice of a team in which they have been placed. Additionally, further scholarship should explore the effectiveness of portfolio-based IPL assessment in general, as well as the relative advantages and disadvantages of the multiple portfolio systems currently in use.

\section{Optimal feedback strategies for IPL}

The current resurgence of interest in feedback in relation to the agency of the learner (Molloy \& Boud 2013) holds considerable potential to enhance learning in the health professions. More 
scholarly inquiry will be required to investigate how this approach might be applied in order to gain the most IPL benefit. This should include consideration of seeking feedback from colearners in other professions, as well as from patients and clients, in addition to facilitators. The question of how the quality of feedback might be measured also warrants further enquiry.

Faculty development for the assessment of IPL outcomes

The approaches and activities required in order to prepare academics and clinicians to implement interprofessional assessment strategies effectively has been very little studied to date and there is an urgent need for scholarly work in this area.

The connection between assessment of IPL and patient-centred care

As Fox and Reeves have noted (2015), the discourses of IPE and patient-centredness intersect and have the potential to reinforce each other in health professional education. Since patient- and client-centredness are seen as having great value in improving the outcomes of health care (Constand et al 2014), further work is required to ascertain the impact of different assessment approaches on the acquisition of this perspective by health professional students.

\section{Conclusion}

This paper has aimed to capture the current global consensus on the assessment of IPL outcomes in preregistration health professional programmes, while we await the further development of theoretical understandings and empirical evidence in this important area. We hope that it will inform local collegial discussions, as health professional educators around the world seek to devise and implement approaches to assess these outcomes in their own students. High quality assessment of IPL, in every setting in which it takes place, can enable educators to ensure that 
their graduates have the capabilities they will need to practice collaboratively and optimise outcomes for their patients, clients and communities.

We invite further feedback from you, our colleagues, as you continue this important work.

\section{Practice points}

- A core group of international IPE leaders utilised two international consultation workshops and a final round of electronic consultation to derive a global consensus statement on the assessment of IPL outcomes

- Points of consensus were achieved to guide interprofessional education programme planners in relation to the purposes of assessment in IPE, its application over the course of a programme of study, what to assess, how to assess, the value of providing feedback and the current gaps in our understanding that require further scholarly enquiry.

\section{Notes on contributors}

GARY D. ROGERS MBBS, PhD is Professor of Medical Education and Deputy Head (Learning \& Teaching) at the School of Medicine, and Program Lead for Interprofessional and SimulationBased Learning at the Health Institute for the Development of Education and Scholarship (Health IDEAS) at Griffith University, Queensland, Australia.

JILL E. THISTLETHWAITE MBBS, PhD is a health professions education consultant, medical adviser at NPS MedicineWise, an Adjunct Professor University Technology Sydney and a practising general practitioner. 
ELIZABETH S. ANDERSON SRN, PhD is Professor of Interprofessional Learning and Patient Safety Lead at Leicester Medical School, UK.

MADELEINE ABRANDT DAHLGREN PhD is Professor of Health Professional Education in the Department of Medicine and Health Sciences at Linköping University, Sweden

RUBY GRYMONPRE PharmD is a Professor in the College of Pharmacy at the University of Manitoba, Manitoba, Canada

MONICA MORAN DocSocSc, MPhil(OccThy) is an Associate Professor and Discipline Lead in Occupational Therapy at Central Queensland University, Australia.

DUJEEPA D. SAMARASEKERA MHPE, FAMS is the Director of the Centre for Medical Education (CenMED) in Yong Loo Lin School of Medicine at the National University of Singapore, Singapore

\section{Acknowledgements}

The authors wish to acknowledge the following colleagues who contributed to one or both of the international workshops conducted to support development of the consensus statement and reviewed a late draft of this paper: Mayumi Asahina (Japan), René Ballnus (Sweden), Christi Barbee (USA), Anthony Breitbach (USA), PC Chan (Australia), Kathy Chappell (USA), Tracy Christopherson (USA), Bronwyn Clark (Australia), Evan Colson (USA), Johanna Dahlburg (Sweden), Lauren DelRossi (USA), Rodney Fawcett (Australia), Kathryn Fitzgerald (Australia), Jenny Ford (UK), Philippa Friary (New Zealand), Gail Furman (USA), Sue Fyfe (Australia), Fraide Ganotice (Hong Kong), Julian Grant (Australia), Carole Haines (Australia), Marietta 
Handgraaf (Germany), Junji Haruta (Japan), Gwen Hollaar (Canada), Kazuichiro Hori (Japan), Bronwen Jones (Australia), Daniel R. Kambey (Indonesia), Sharla King (Canada), Bente Kvilhaugsvik (Norway), Neena Lakhani (UK), Sylvia Langlois (Canada), Susanne Lindqvist (UK), Tai Yuen Ling (Singapore), Dean Lising (Canada), Bronwyn Maddock (Australia), Cornelia Mahler (Germany), Steve Malcherczyk (UK), Minna Manninen (Finland), Mira Mette (Germany), Jennifer Newton (Australia), Ghada Said Mohammed Omar (Denmark), Mary Padden (USA), Andrew Papanikitas (UK), Kunal Patel (UK \& Ireland), Nivritti Patil (Hong Kong), John Pugsley (Canada), Sue Pullon (New Zealand), Kate Regnier (USA), Lorna Rosenwax (Australia), Ikuko Sakai (Japan), Adrian Schoo (Australia), Dale Sheehan (New Zealand), Lawrence Sherman (USA), Toshinori Shimoi (Japan), Brian Simmons (Canada), Heather Simmons (Canada), Kay Skinner (Australia), Margaret Slusser (USA), Melanie Stephens (UK), Tiina Tervaskanto-Mäentausta (Finland), Jo Thomas (Australia), Yashushi Uchiyama (Japan), Essi Varkki (Finland), Susan Wagner (Canada), Pamela Walsh (USA), Helena Ward (Australia), Jennifer Wise (USA), Jewelry Yep (USA), Ali Yildirim (UK).

\section{Declarations of Interest}

The authors report no formal declarations of interest. The work of several of the authors is quoted, and in some cases endorsed, in this document; where this is the case the material was included by consensus of the remaining authors who had not contributed to the cited work. 


\section{References}

All Together Better Health 5 International Conference participants. 2010. The Sydney Interprofessional Declaration [Internet]. Sydney (Australia): Australasian Interprofessional Practice and Education Network; [cited 2016 Jul 15]. Available from: http://www.aippen.net/the-sydney-interprofessional-declaration-2010

Anderson ES, Ford J, Thorpe LN. 2011. Learning to Listen: Improving students' communication with disabled people. Med Teach. 32:1-9.

Anderson ES, Lennox A. 2009. The Leicester Model of interprofessional education: Developing, delivering and learning from student voices for 10 years. J Interprof Care. 23:557-573.

Anderson ES, Smith R, Hammick M. 2015. Evaluating an interprofessional education curriculum: A theory-informed approach. Med Teach. 36:495-504.

Association of Faculties of Medicine of Canada. 2010. The Future of Medical Education in Canada (FMEC): A Collective Vision for MD Education [Internet]. Ottawa (Canada): Association of Faculties of Medicine of Canada; [cited 2016 Jul 15]. Available from: https://www.afmc.ca/pdf/fmec/FMEC-MD-2015.pdf

Australian Medical Council. 2014. Intern training - term assessment form [Internet]. National Internship Framework. Canberra (Australia); [cited 2017 Jul 17]. Available from: http://www.amc.org.au/accreditation/prevoc-standards

Barr H. 1996. Ends and means in interprofessional education: Towards a typology. Educ Health. $9: 341-352$.

Barr H, Ross F. 2006. Mainstreaming interprofessional education in the United Kingdom: a position paper. J Interprof Care. 20:96-104. 
Barr H, Gray R, Helme M, Low H, Reeves S. 2016. Interprofessional Education Guidelines. Fareham (UK): Centre for the Advancement of Interprofessional Education.

Biggs JB, Tang C. 2007. Teaching for quality learning at university. $3^{\text {rd }}$ ed. Maidenhead (UK): McGraw-Hill.

Bloom BS, Engelhart MD, Furst EJ, Hill WH, Krathwohl DR. 1956. Taxonomy of educational objectives: The classification of educational goals. Handbook I: Cognitive domain. New York: David McKay Company.

Boud D. 2000. Sustainable Assessment: Rethinking assessment for the learning society. Stud Cont Educ. 22:151-167.

Boyce RA, Moran MC, Nissen LM, Chenery HJ, Brooks PM. 2009. Interprofessional education in health sciences: the University of Queensland Health Care Team Challenge. Med J Aust. 190:433-436.

Bridges DR, Davidson RA, Odegard PS, Maki IV, Tomkowiak J. 2011. Interprofessional collaboration: three best practice models of interprofessional education. Med Educ Online [Internet]. [cited 2015 Jul 15]; 16. Available from: http://med-edonline.net/index.php/meo/article/view/6035

[CAIPE] Centre for the Advancement of Interprofessional Education. 2002. Defining IPE [Internet]. Fareham (UK): Centre for the Advancement of Interprofessional Education; [cited 2016 Jul 18]. Available from http://www.caipe.org.uk/about-us/definingipe/?keywords $=$ principles

Canadian Medical Association. 2007. Putting patients first: Patient centred collaborative care a discussion paper [Internet]. Ottawa (Canada): Canadian Medical Association; [cited 2015 
Jul 15]. Available from:

http://fhs.mcmaster.ca/surgery/documents/CollaborativeCareBackgrounderRevised.pdf

Carlisle C, Cooper H, Watkins C. 2004. 'Do none of you talk to each other?' the challenges facing the implementation of interprofessional education. Med Teach, 26:545-552.

[CIHC] Canadian Interprofessional Health Collaborative. 2010. A National Interprofessional Competency Framework [Internet]. Vancouver (Canada): University of British Columbia; [cited 2016 Jul 18]. Available from: http://www.cihc.ca/files/CIHC_IPCompetencies_Feb1210.pdf

[CIHC] Canadian Interprofessional Health Collaborative. 2012. An Inventory of Quantitative Tools Measuring Interprofessional Education and Collaborative Practice Outcomes [Internet]. Vancouver (Canada): University of British Columbia; [cited 2016 Jul 17]. Available from: http://rcrc.brandeis.edu/pdfs/Canadian\%20Interprofessional\%20Health\%20Collaborative\% 20report.pdf

[CIHC] Canadian Interprofessional Health Collaborative. 2016. Accreditation of Interprofessional Health Education [Internet]. Vancouver (Canada): University of British Columbia; [cited 2016 Oct 14]. Available from: http://www.cihc.ca/aiphe

College of Health Disciplines, University of British Columbia. 2014. The Interprofessional Passport Guide [Internet]. Vancouver (Canada): University of British Columbia; [cited 2016 Jul 17]. Available at: http://physicaltherapy.med.ubc.ca/files/2012/05/TheInterprofessional-Passport-Guide.pdf 
Constand MK, MacDermid JC, Dal Bello-Haas V, Law M. 2014. Scoping review of patientcentered care approaches in healthcare. BMC Health Serv Res. 14:271.

Cruess RL, Cruess SL. 2008. Expectations and obligations: Professionalism and medicine's social contract with society. Perspect Biol Med. 51:579-598.

[CUILU] Combined Universities Interprofessional Collaboration Unit. 2006. Interprofessional capability framework. Sheffield (UK): The Combined Universities Interprofessional Learning Unit.

Curran V, Deacon D, Fleet L. 2005. Review, assessment and recommendations of accreditation standards, policies, and practices as they relate to interprofessional education for collaborative patient-centered practice (IECPCP). Ottawa (Canada): Health Canada.

Curran V, Hollett A, Casimiro LM, Mccarthy P, Banfield V, Hall P, Lackie K, Oandasan I, Simmons B, Wagner S. 2011. Development and validation of the interprofessional collaborator assessment rubric (ICAR). J Interprof Care. 25:339-344.

Curtin University. 2010. Interprofessional Capability Framework [Internet]. Perth (Australia): Curtin University; [cited 2016 Jul 17]. Available from http://healthsciences.curtin.edu.au/wpcontent/uploads/sites/6/2015/10/interprofessional_A5_broch_1-29072015.pdf

Dixon-Woods M. 2010. Why is patient safety so hard? A selective review of ethnographic studies. J Health Serv Res Policy. 15:11-16.

Domac S, Anderson ES, O’Reilly M, Smith R. 2015. Assessing Interprofessional Competence Using a Prospective Reflective Portfolio. J Interprof Care. 29:179-187. 
Domac S, Anderson ES, Smith R. Forthcoming 2016. Learning to be interprofesional through the use of reflective portfolios? J Soc Work Educ.

Dornan T, Boshuizen H, King N, Scherpbier A. 2007. Experience-based learning: a model linking the processes and outcomes of medical students' workplace learning. Med Educ. 41:84-91.

Dunworth M. 2007. Joint assessment in inter-professional education: A consideration of some difficulties. Soc Work Educ. 26:414-22

Finnemann M, Holtzmann JS, Hovedskov J. 2016. An interprofessional competency framework: a way to open the silos in health care and build bridges between practice, policy and strategy. Poster (TN24) presented at All Together Better Health VIII conference, Oxford, UK.

Fox A, Reeves S. 2015. Interprofessional collaborative patient-centred care: a critical exploration of two related discourses. J Interprof Care. 29:113-8.

Frank JR, Mungroo R, Ahmad Y, Wang M, De Rossi S, Horsley T. 2010. Toward a definition of competency-based education in medicine: a systematic review of published definitions. Med Teach. 32:631-7.

Fraser SW, Greenhalgh T. 2001. Coping with complexity: Educating for capability. BMJ. 323:799-803.

Freeman M, McKenzie J. 2002. SPARK, a confidential web-based template for self and peer assessment of student teamwork: benefits of evaluating across different subjects. Br J Educ Technol. 33:551-69.

Freeth D. 2001. Sustaining interprofessional collaboration. J Interprof Care. 15:37-46. 
Frenk J, Chen L, Bhutta ZA, Cohen J, Crisp N, Evans T, Fineberg H, Garcia P, Ke Y, Kelley P, et al. 2010. Health professionals for a new century: transforming education to strengthen health systems in an interdependent world. Lancet. 376:1923-1958.

Gelmon SB, O’Neil EH, Kimmey JR, Task Force on Accreditation of Health Professions Education. 1999. Strategies for change and improvement: The report of the task force on accreditation of health professions education. San Francisco: Center for the Health Professions, University of California at San Francisco.

General Medical Council. 2012. The good medical practice framework for appraisal and revalidation [Internet]. Manchester (UK): General Medical Council; [cited 2016 Jul 17]. Available from: http://www.gmc-uk.org/doctors/revalidation.asp

Gilbert JHV. 2005. Interprofessional learning and higher education structural barriers. J Interprof Care, 19(Supl):87-106.

Gilbert J. 2014. Interprofessional education in Canada: Initiatives 2003-2011. In: Forman D, Jones M, Thistlethwaite JE, editors. Leadership Development for Interprofessional Education and Practice. Basingstoke (UK): Palgrave; p. 26-46.

Graffam B. 2007. Active learning in medical education: Strategies for beginning implementation. Med Teach. 29:38-42.

Grymonpre RE. Forthcoming 2016. Point/counter-point. Are pharmacy students learning to be effective collaborators to work within health care teams through our IPE initiatives? Can J Hosp Pharm. 
Hall P, Marshall D, Weaver L, Boyle A, Taniguchi A. 2011. A method to enhance student teams in palliative care: piloting the McMaster-Ottawa Team Observed Structured Clinical Encounter. J Palliat Med. 14:744-750.

Hammick M, Freeth D, Copperman J, Goodsman D. 2009. Being Interprofessional. Cambridge (UK): Polity Press.

Haruta J, Goto M, Mori Y, Ichikawa S, Yoshida K, Yoshmi K, Yoshimoto H. 2016. Development of an interprofessional competency framework in Japan. Poster (WN33) presented at All Together Better Health VIII conference, Oxford, UK.

Health Force Ontario. 2010. Implementing interprofessional care in Ontario: Final report of the interprofessional care strategic implementation committee. Toronto (Canada): Health Force Ontario; [cited 2015 Jul 15]. Available from:

http://www.ipe.uwo.ca/Administration/teachings/HFO\%20IPC\%20Final\%20Report\%202 010.pdf.

Herbert CP. 2005. Changing the culture: Interprofessional education for collaborative patientcentred practice in Canada. J Interprof Care. 19(supl):1-4.

Imanipour M, Jalili M. 2016. Development of a comprehensive clinical performance assessment system for nursing students: A programmatic approach. Jpn J Nurs Sci. 13:46-54.

Interprofessional Curriculum Renewal Consortium. 2013. Curriculum Renewal for Interprofessional Education in Health [Internet]. Sydney (Australia): Centre for Research in Learning and Change, University of Technology Sydney; [cited 2016 Jul 15]. Available from: http://caipe.org.uk/silo/files/ipecurriculum-renewal-20141.pdf 
Interprofessional Education Collaborative. 2016. Core Competencies for Interprofessional Collaborative Practice: 2016 update [Internet]. Washington, DC: Interprofessional Education Collaborative; [cited 2016 Sep 29] Available at: http://www.aacn.nche.edu/education-resources/IPEC-2016-Updated-Core-CompetenciesReport.pdf

[IOM] Committee on Measuring the Impact of Interprofessional Education on Collaborative Practice and Patient Outcomes, Board on Global Health, Institute of Medicine. 2015. Measuring the impact of interprofessional education on collaborative practice and patient outcomes. Washington, DC: National Academies Press.

[IPEC] Interprofessional Education Collaborative Expert Panel. 2011. Core Competencies for Interprofessional Collaborative Practice: Report of an Expert Panel [Internet]. Washington, DC: Interprofessional Education Collaborative; [cited 2016 Jul 17] Available from: http://www.aacn.nche.edu/education-resources/ipecreport.pdf

iTOFT Consortium, Australia. 2015. Work based assessment of teamwork: an interprofessional approach. Canberra (Australia): Australian Government, Office for Learning and Teaching.

Joint Accreditation [Internet]. 2013. Chicago: Joint Accreditation [cited 2016 Oct 13]. Available from: http://www.jointaccreditation.org/about-joint-accreditation.

Kassebaum DG. 1992. Origin of the LCME, the AAMC-AMA partnership for accreditation. Acad Med. 67:85-7.

Kassebaum DG, Cohen JJ. 2000. Nonaccredited medical education in the United States. N Engl J Med. 342:1602-1605. 
Krathwohl DR, Bloom BS, Masia BB. 1956. Taxonomy of educational objectives, Handbook II: affective domain. New York: David McKay Company Inc.

Ladden MD, Bednash G, Steves DP, Moore, G.T. (2006). Educating interprofessional learners for quality, safety and systems improvement. J Interprof Care. 20:497-505.

Lurie S. 2012. History and practice of competency-based assessment. Med Educ. 46:49-57.

Mahler C, Berger S, Reeves S. 2015. The Readiness for Interprofessional Learning Scale (RIPLS): A problematic evaluative scale for the interprofessional field. J Inteprof Care. 29:289-291.

Manidis M, Slade D, McGregor J, Chandler E, Dunston R, Scheeres H, Stein-Parbury J, Iedema R, Stanton N. 2009. Emergency Communication: Report for Prince of Wales Hospital. Sydney (Australia): University of Technology Sydney

Mann K, Gordon G, MacLeod A. 2009. Reflection and reflective practice in health professions education: a systematic review. Adv Health Sci Educ Theory Pract. 14:595-621.

McLachlan JC. 2006. The relationship between assessment and learning. Med Educ. 40:716-777.

Miller GE. 1990. The assessment of clinical skills/competence. Acad Med. 65:s63-s67.

Molloy E, Boud D. 2013. Changing conceptions of feedback. In: Boud D, Molloy E, editors. Feedback in Higher and Professional Education. London (UK): Routledge. p. 11-33.

Morrissey S, Rogers GD, Chan PC, Kerkow EJ, Desbrow B. 2014. Establishing 'health professions literacy': Evaluation of a video-based learning package in a three-phase curriculum. Paper presented at All Together Better Health VII conference, Pittsburg, USA. 
Muijtjens AMM, Hoogenbook RJI, Verwijnen GM, Van der Vleuten CPM. 1998. Relative or absolute standards in assessing medical knowledge using progress tests. Adv Health Sci Educ Theory Pract. 3:81-7.

NHS Education for Scotland. 2016. Walk through NHS ePortfolio [Internet]. Edinburgh (UK): NHS Education for Scotland; [cited 2016 Jul 17]. Available from: http://guide.nhseportfolios.org/walkthrough/Home.aspx

Norcini JJ, Blank LL, Duffy FD, Fortna G. 2003. The mini-CEX: a method for assessing clinical skills. Ann Intern Med. 138:476-481.

Oakley B, Felder RM, Brent R, Elhajj I. 2004. Turning student groups into effective teams. J Stud Cent Learn. 2:9-34.

Oandasan I, Reeves S. 2005. Key elements for interprofessional education. Part 1: The learner, the educator and the learning context. J Interprof Care. 19(s1): 21-38.

Oates M, Davidson M. 2014 A critical appraisal of instruments to measure outcomes of interprofessional education. Med Educ. 49:386-98.

O’Keefe M, Henderson A, Jolly B, McAllister L, Remedios L, Chick R. 2014. Threshold learning outcomes: a framework for incorporating professional accreditation and AQF standards into assessment blueprinting/mapping in healthcare disciplines. Sydney (Australia): Office of Learning and Teaching.

Parsell G, Bligh J. 1999 The development of a questionnaire to assess the readiness for health care students for interprofessional learning (RIPLS). Med Educ. 33: 95-100. 
Paterno E, Opina-Tan L. 2014. Developing community-based interprofessional education in the Philippines. In: Forman D, Jones M, Thistlethwaite JE, editors. Leadership Development for Interprofessional Education and Practice. Basingstoke (UK): Palgrave; p. 162-178.

Reeves S. 2012. The rise and rise of interprofessional competence. J Interprof Care. 26:253-255.

Reeves S, Perrier L, Goldman J, Freeth D, Zwarenstein M. 2013. Interprofessional education: Effects on professional practice and healthcare outcomes (update). Cochrane Database Syst Rev 2013:1-47.

Reeves S, Pelone F, Hendry J, Lock N, Marshall J, Pillay L, Wood R. Forthcoming 2016. Using a meta-ethnographic approach to explore the nature of facilitation and teaching approaches employed in interprofessional education. Med Teach.

Rogers GD. 2011. An implementation framework for interprofessional learning at Griffith Health 2011 - 2014 [Internet]. Gold Coast (Australia): Health Institute for the Development of Education and Scholarship (Health IDEAS), Griffith University; [cited 2016 Jul 18]. Available from: https://www.griffith.edu.au/_data/assets/pdf_file/0010/475768/GriffithHealthIPLFrame work.pdf

Rogers GD, Chan PC, Ellem F. 2012. Impacts of interprofessional simulation on affective learning among medical students: Qualitative analysis from the CLEIMS study. Paper presented at: the Australian and New Zealand Association for Health Professional Education conference, Rotorua, New Zealand. 
Rogers GD, McConnell HW, Jones de Rooy N, Ellem F, Lombard M. 2014a. A randomised controlled trial of extended immersion in multi-method continuing simulation to prepare senior medical students for practice as junior doctors. BMC Med Educ. 14:90.

Rogers GD, Chan PC, Ellem F, Lombard M. 2014b Charting inspiration: development and evaluation of a tool to measure health professional student learning in the affective domain. Paper presented at: Excellence in education - The 21st Century Teacher. International Association for Medical Education (AMEE) congress, Milan, Italy.

Schmitz C, Brandt B. 2015. To RIPLS or Not to RIPLS: That is Only Part of the Question [Internet]. Minneapolis: National Center for Interprofessional Practice and Education; [cited 2016 Jul 17]. Available from: https://nexusipe.org/informing/about-nationalcenter/news/ripls-or-not-ripls-only-part-question

Schwarz MR. 1992. Liaison committee on medical education: Past successes, future challenges. JAMA. 268:1091-1092.

Simmons B, Egan-Lee E, Wagner SJ, Esdaile M, Baker L, Reeves S. 2011. Assessment of interprofessional learning: the design of an interprofessional objective structured clinical examination (iOSCE) approach. J Interprof Care. 25:73-74.

Solomon P, Marshall D, Boyle A, Burns S, Casimiro LM, Hall P, Weaver L. 2011. Establishing face and content validity of the McMaster-Ottawa team observed structured clinical encounter (TOSCE). J Interprof Care. 25:302-304.

Steinert Y. 2005. Learning together to teach together: Interprofessional education and faculty development. J Interprof Care. 19(s1):60-75. 
Symonds I, Cullen L, Fraser D. 2003. Evaluation of a formative interprofessional team objective structured clinical examination (ITOSCE): A method of shared learning in maternity education. Med Teach. 25:38-41.

ten Cate O, Snell L, Carraccio C. 2010. Medical competence: the interplay between individual ability and the health care environment. Med Teach. 32:669-675.

Teodorczuk A, Khoo TK, Morrissey S, Rogers GD. 2016. Developing interprofessional education: Putting theory into practice. Clin Teach. 13:7-12.

Thistlethwaite JE. 2015. Assessment of interprofessional teamwork - an international perspective. In: Forman D, Jones M, Thistlethwaite JE, editors. Leadership and Collaboration. Basingstoke (UK): Palgrave; p. 35-152.

Thistlethwaite J, Dallest K, Moran M, Dunston R, Roberts C, Eley D, Bogossian F, Forman D, Bainbridge L, Drynan D, Fyfe S. Introducing the individual Teamwork Observation and Feedback Tool (iTOFT): Development and description of a new interprofessional teamwork measure. J Interprof Care. 30:526-8.

Thistlethwaite JE, Forman D, Matthews LR, Rogers GD, Steketee C, Yassine T. 2014. Competencies and frameworks in interprofessional education: A comparative analysis. Acad Med. 89: 869 - 875.

Thistlethwaite JE, Moran M, Kumar K, Saunders R, Carr S. 2015. An exploratory review of prequalification interprofessional education evaluations. J Interprof Care. 29:292-297.

Thompson BM, Gonzalo JD, Levene RE. 2016. The power of the written word: team assessment of behaviour. Med Educ. 50:702-708. 
[UCSF] University of California, San Francisco. 2014. Framework \& competencies [Internet]. San Francisco: University of California, San Francisco Program for Interprofessional Practice and Education; [cited 2016 Jul 17]. Available at: https://interprofessional.ucsf.edu/framework-competencies van der Vleuten CP, Schuwirth LW. 2005. Assessing professional competence; from methods to programmes. Med Educ. 39:309-317.

van de Ridder JMM, McGaghie WC, Stokking KM, ten Cate OTJ. 2015. Variables that affect the process and outcome of feedback, relevant for medical training: a meta-review. Med Educ. 49:658-673.

van Dongen JJJ, Lenzen SA, van Bokhoven MA, Daniëls R, van der Weijden T, Beurskens A. 2016. Interprofessional collaboration regarding patients' care plans in primary care: a focus group study into influential factors. BMC Fam Pract. [Internet]. [cited 2015 Jul 15]; 17: 58. Available from: http://bmcfampract.biomedcentral.com/articles/10.1186/s12875-016-04565

Wilhelmsson M, Pelling S, Ludvigsson J, Hammar M, Dahlgren L, Faresjö Y. 2009. Twentyyears experience of interprofessional education in Linköping - ground breaking and sustainable. J Interprof Care. 23: 121-133.

Wilson T, Holt T. 2001. Complexity and clinical care. BMJ. 323:685-688.

[WHO] World Health Organization. 2010. Framework for action on interprofessional education \& collaborative practice [Internet]. Geneva (Switzerland):World Health Organization; [cited 2015 Jul 15]. Available from: http://www.who.int/hrh/resources/framework_action/en/ 
Zwarenstein M, Goldman J, Reeves S. 2009. Interprofessional collaboration: Effects of practicebased interventions on professional practice and healthcare outcomes. Cochrane Database Syst Rev 2009:1-3. 
Table, Figures and Boxes

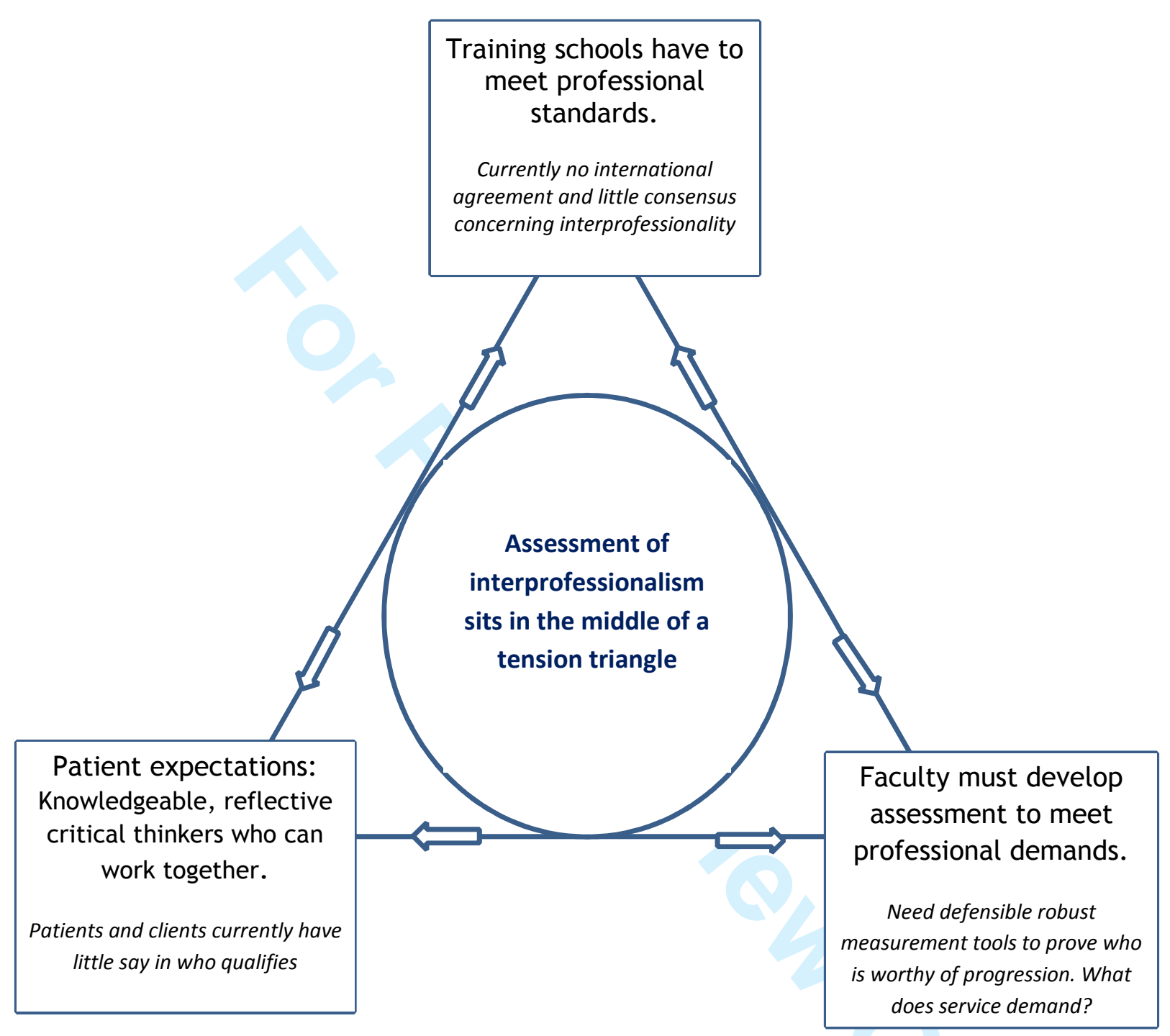

Figure 1: Tension triangle between professional body requirements, service requirements and patient expectations 


\begin{tabular}{|c|c|c|c|}
\hline Framework & Reference & Terminology & Domains \\
\hline $\begin{array}{l}\text { UK (2004) } \\
\text { Interprofessional } \\
\text { Capability Framework }\end{array}$ & (CIULU 2006) & Capability & $\begin{array}{l}\text { - Knowledge in practice } \\
\text { - Ethical practice } \\
\text { - Interprofessional working } \\
\text { - Reflection (learning) }\end{array}$ \\
\hline $\begin{array}{l}\text { Canada (2010) } \\
\text { National } \\
\text { Interprofessional } \\
\text { Competency } \\
\text { Framework }\end{array}$ & (CIHC 2010) & Competence & $\begin{array}{l}\text { Interprofessional } \\
\text { communication } \\
\text { - Patient-/client-centred } \\
\text { care } \\
\text { - Role clarification } \\
\text { - Team functioning } \\
\text { - Collaborative leadership } \\
\text { - Interprofessional conflict } \\
\text { resolution }\end{array}$ \\
\hline $\begin{array}{l}\text { USA (2011, updated } \\
\text { 2016) } \\
\text { Core Competencies } \\
\text { for Interprofessional } \\
\text { Collaborative Practice }\end{array}$ & $\begin{array}{l}\text { (Interprofessional } \\
\text { Education } \\
\text { Collaborative } \\
\text { 2016) }\end{array}$ & Competence & $\begin{array}{l}\text { - Values and ethics } \\
\text { - Roles and responsibilities } \\
\text { - Interprofessional } \\
\text { communication } \\
\text { - Teamwork and team based } \\
\text { care }\end{array}$ \\
\hline $\begin{array}{l}\text { Australia (2010) } \\
\text { Interprofessional } \\
\text { Capability Framework }\end{array}$ & $\begin{array}{l}\text { (Curtin University } \\
2010 \text { ) }\end{array}$ & Capability & $\begin{array}{l}\text { - Communication } \\
\text { - Team function } \\
\text { - Role clarification } \\
\text { - Conflict resolution } \\
\text { - Reflection }\end{array}$ \\
\hline
\end{tabular}

Table 1 Some thematic frameworks (adapted from Thistlethwaite 2014) 
http://guide.nhseportfolios.org/walkthrough/Home.aspx

http://physicaltherapy.med.ubc.ca/files/2012/05/The-Interprofessional-PassportGuide.pdf

https://uwaterloo.ca/pharmacy/waterloo-ipe

http://www.ncbi.nlm.nih.gov/pubmed/25421452

http://tiger.library.dmu.ac.uk/Example\%20Portfolio\%20for\%20students\%20at\%20 Leicester-Northants-Demontfort\%20Unis.pdf https://tiger.library.dmu.ac.uk/Assessment\%20Designing\%20a\%20Portfolio.pdf http://www.utmb.edu/ipep/PDFs/Scholars\%20Handbook.pdf https://www.keele.ac.uk/health/interprofessionaleducation/ 18]. 